\title{
Space, time and complexity in plant dispersal ecology
}

\author{
Juan J Robledo-Arnuncio ${ }^{1 *}$, Etienne K Klein ${ }^{2}$, Helene C Muller-Landau ${ }^{3}$ and Luis Santamaría ${ }^{4}$
}

\begin{abstract}
Dispersal of pollen and seeds are essential functions of plant species, with far-reaching demographic, ecological and evolutionary consequences. Interest in plant dispersal has increased with concerns about the persistence of populations and species under global change. We argue here that advances in plant dispersal ecology research will be determined by our ability to surmount challenges of spatiotemporal scales and heterogeneities and ecosystem complexity. Based on this framework, we propose a selected set of research questions, for which we suggest some specific objectives and methodological approaches. Reviewed topics include multiple vector contributions to plant dispersal, landscape-dependent dispersal patterns, long-distance dispersal events, spatiotemporal variation in dispersal, and the consequences of dispersal for plant communities, populations under climate change, and anthropogenic landscapes.
\end{abstract}

Keywords: Seed, Pollen, Gene flow, Dispersal kernel, Migration, Long-distance dispersal, Community ecology, Climate change

\section{Introduction}

Pollen and seed dispersal are essential functions of plants, with far-reaching consequences for reproduction, population and community dynamics, neutral and adaptive evolution and, ultimately, population and species persistence. Because an understanding of gene and individual movement capacities is critical to predicting the response of individuals, populations and species to ecosystem perturbation and climate change, the long-standing interest in plant dispersal has seen an upsurge in recent years. Extensive monographs have recently dealt with the ecology and evolution of dispersal of organisms in general [1] and of plants in particular [2]. Other more specific reviews (many of which are cited below) have focused on the mechanisms, consequences and measurement of passive and animal-mediated plant dispersal, considering different spatial and temporal scales and varied ecological, demographic and evolutionary settings.

Here, we pose eight general questions that we believe will define some of the research frontiers in plant movement ecology in the coming years. We do not attempt to

\footnotetext{
* Correspondence: jjrobledo@gmail.com

1 Department of Forest Ecology \& Genetics, INIA-CIFOR, Ctra. de la Coruña km 7.5, 28040 Madrid, Spain

Full list of author information is available at the end of the article
}

answer these questions, or to exhaustively review the stateof-the-art in these areas, but rather offer our perspectives regarding a selection of important research topics, with an emphasis on specific empirical objectives and methods. The paper is oriented along three axes, representing three fundamental dimensions that challenge ecological inference and models in general, and dispersal ecology research in particular: space, time and complexity (Figure 1). Spatial scale and heterogeneity issues typically arise in longdistance dispersal (LDD) estimation and modeling, but also when characterizing dispersal variation among individuals, populations and regions, when assessing landscape effects on dispersal, or when measuring dispersal anisotropy. Temporal issues are inherent in studies examining dispersal fluctuations across years or dispersal seasons, and also arise when building up dispersal kernels from descriptions of instantaneous vector movement, when obtaining robust estimates of dispersal variation among individuals or populations, when inferring historical migration rates from genetic data, and when predicting long-term feedbacks between dispersal, demography and evolution. The dynamic complexity of environments, communities and ecosystems pervades most aspects of dispersal ecology research, from pollinator and seeddisperser networks, through the consequences of dispersal 


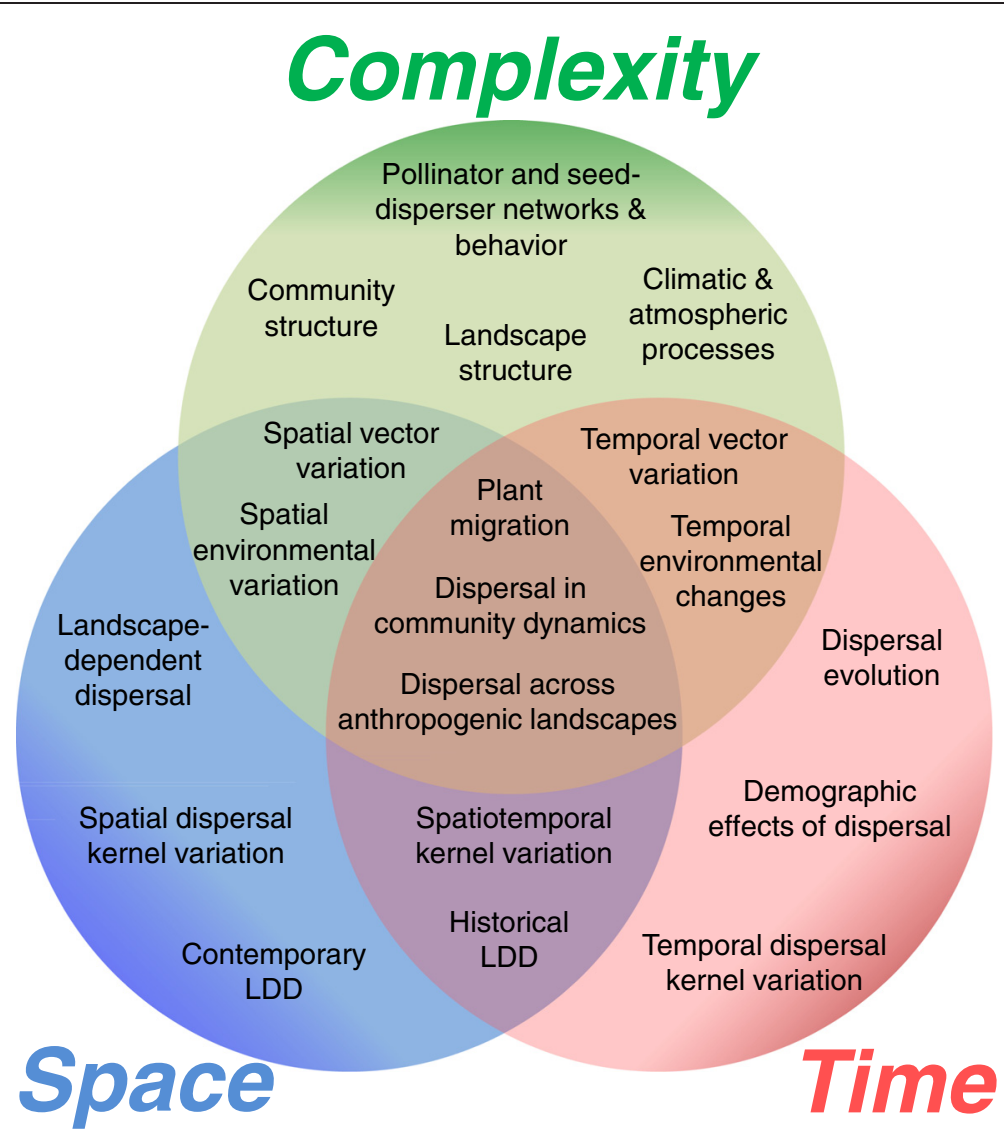

Figure 1 Diagram of plant dispersal research topics considered in this study, each of which confronts challenges of spatial scale and heterogeneity, temporal scale and/or system complexity.

for population and community dynamics, to dispersal sensitivity to global change (Figure 1).

Within this broad framework, we first argue that mechanistically accounting for the relative contribution of multiple vectors to dispersal of particular plant species constitutes an essential basis for explaining and predicting dispersal patterns in spatiotemporally changing ecosystems (Section 1). Next, we examine how the interplay between vectors and environmental heterogeneity determine landscape-dependent seed and pollen deposition patterns that are missed by pure distance-dependent models (Section 2). We then focus on the broadest spatial scale by examining the measurement of longdistance dispersal across species' ranges (Section 3). We continue by addressing the causes and consequences of variability in dispersal patterns among individuals and populations (Section 4), and over time (Section 5). Finally, we take a broader temporal perspective to consider the consequences of dispersal for plant communities (Section 6), populations under climate change (Section 7), and anthropogenic landscapes (Section 8).

\section{Review}

1. What are the contributions of different vectors to plant dispersal?

It is now acknowledged that for many if not most plant species multiple vectors contribute to dispersal [3]: polychory (seed dispersal by multiple animal vectors) is widespread [4], ambophily (pollination by insects and wind) might be more common than previously thought [5], and mutualistic networks confirm the diversity of animal pollinators [6]. Knowing the variety of vectors for the species of interest is an essential initial step of dispersal studies, because different vectors may disperse propagules (defined here as pollen, seeds or spores) over contrasting spatial scales [7-9], their activity may fluctuate over different spatial and temporal scales, and they may respond differently to environmental and demographic changes. Of special interest is identifying vectors, vector characteristics, or environmental conditions responsible for LDD events, because they often result from nonstandard dispersal conditions [3,4,10-13] and contribute disproportionately to demography and population genetics (see Section 3). However, most intraspecific studies of seed and pollen dispersal have focused on a single vector. 
The relative contribution of multiple vectors to dispersal can be investigated using empirical and modelling approaches. Dispersal kernels (i.e. the probability distribution of dispersal locations relative to the source location) can be estimated empirically based on direct observation of propagule deposition patterns at a sample of settling locations (Eulerian methods), or by tracking individual propagules (Lagrangian methods), most frequently over short to intermediate scales (e.g. [2,14-19]). Assessing the contribution of multiple vectors to dispersal based on these methods involves pairing each propagule deposition or transport event with the responsible vector, which may not be easy in practice. A few recent studies provide good examples of how to empirically investigate the contribution of multiple animal vectors to seed [20-23] and pollen [24] dispersal kernels, and we expect to see more such efforts in the future, including replication over different landscape configurations, environments and dispersal seasons. A complementary and more explanatory approach consists in modeling the dispersal kernel from mechanistic (process-based) considerations [25], and calibrating it using Eulerian [26] or Lagrangian [27] data. Mechanistic models provide excellent tools for evaluating the relative importance of different dispersal vectors, because they involve (i) inventorying the biological, ecological and environmental factors that impact propagule paths from emission to final deposition, and (ii) quantifying the probabilities associated with the different factors. For example, if wind speed, settling velocity and release height are fixed, the ballistic equation provides a unique dispersal location for a propagule passively dispersed by wind, assumed to follow a deterministic linear path. Integrating over probability distributions for wind speed, release height, propagule mass and area then results in a dispersal kernel $[26,28]$. Similarly, propagule dispersal by different animal vectors can be modeled with dispersal kernels that integrate observations of disperser movement and foraging behavior with models of seed retention [21] or pollen carry-over [29].

Mechanistic approaches are valuable for understanding landscape-dependent dispersal patterns (Section 2) and the occurrence of patchy or clumped dispersal resulting from correlated movement of propagules [30]. They are particularly useful for investigating LDD events and their associated vectors, because they can potentially inform accurate extrapolation to larger scales than those observed [25] (see Section 3). They can also assist in predicting the effects of spatiotemporal variation in the environment and in plant phenotypes on vector behavior and the distribution of dispersal distances (Sections 4 and 5). Future studies should further exploit mechanistic methods to (i) investigate the extent to which dispersal kernels are dynamic distributions subject to temporal and environmental influence, and (ii) identify the critical vectors and environmental variables with disproportionate impact on dispersal probabilities over short and long distances. For this purpose, it will be important to validate mechanistic predictions with alternative methods (e.g., direct observations or genetic approaches; see Section 3) over different spatial and temporal scales, and to cross-validate with independent data sets.

\section{How can we better characterize landscape-dependent variation in seed and pollen deposition, and how can we better evaluate its consequences?}

Historically, most studies of seed and pollen dispersal have described dispersal patterns exclusively in terms of the distribution of deposition distances from sources (e.g. $[15,31])$. Clearly, distance from sources is important in explaining variation in propagule deposition, and dispersal distance is also critical in determining the consequences of dispersal [32,33]. However, distance generally explains only a small fraction of variation in seed [34] or pollen [35] densities. The unexplained variation is important for post-dispersal success of individual seeds or pollen grains, and for population and community processes and patterns [36-38]. A considerable portion of this variation can be assigned to deterministic factors such as direction and habitat characteristics $[39,40]$, and/or explained by contextdependent mechanistic models incorporating landscape heterogeneity and vector movement characteristics $[41,42]$. Yet our methods for describing and modeling these patterns remain fairly limited, and theoretical studies have done little to elucidate their consequences.

In many systems, the probability of a seed ending up in a particular location depends on the type of substrate or habitat at that location - deposition is essentially habitat-specific [34]. A special case of this is when seeds are disproportionately deposited in habitats favorable for seed and seedling success; this "directed dispersal" has received considerable attention [39]. Yet this is just a small part of a larger phenomenon, with little attention to the opposite pattern of disproportionate dispersal to less favorable habitats. For example, several much-cited studies document directed dispersal into canopy gaps in a few neotropical forest taxa [43]. However, a community-level study found that overall seed arrival in gaps was much lower than seed arrival in the shaded understory for all functional groups [44]. Habitat-specific dispersal is common in both wind- and animal-dispersed seeds and pollen. For wind dispersal, habitat-specific deposition may result from the way in which seed or pollen movement is affected by topography and canopy structure [42,45-48], and/or by substrate characteristics determining the likelihood of secondary dispersal by wind [49]. For animal-mediated dispersal, habitat-specific deposition results from habitat preferences of seed dispersers or pollinators, both for movement in general [50,51], and for activities 
related to deposition (in the case of seeds), such as caching and defecating [52].

A challenge for modelling habitat-specific deposition is that deposition probabilities depend not only on fine-scale local habitat heterogeneities, but also on the habitat matrix of a larger area [53]. Thus increasing or decreasing propagule deposition probability by a fixed factor depending on habitat is too simplistic. Schurr et al. [54] address this challenge by first transforming physical space into "movement space", reflecting areas of low and high permeability to (seed) flow by wind, and then evaluating dispersal kernels in this transformed space; this approach seems well-suited to modelling wind dispersal of both pollen and seeds. For animal dispersal, detailed spatially explicit models can simulate the influences of animal behavior and habitat structure on seed $[41,50,55,56]$ and pollen $[29,51]$ dispersal patterns. The parameterization and application of such models has become ever easier due to advances in animal tagging and telemetry, remote sensing (including accurate geo-referencing), and computation [43,57-60]. A key limitation is that such models are generally based on purely phenomenological descriptions of animal displacement kernels and habitat choice. Future research should aim to develop mechanistic descriptions of the processes behind such patterns, including internal motivation, memory, territoriality, and propagule retention (e.g. seed digestion, [61]) time models, thereby allowing for extrapolation to other spatial and temporal contexts [62]. These models could build on the extensive literature on animal movement ecology, which remains under-utilized to date by scholars working on plant dispersal [63-65].

Seed and pollen dispersal are also often anisotropic [66-71], whereas the standard distance-only models assume direction does not matter. Directional bias increases clustering and may thereby reduce the benefits of dispersal [37]. Importantly, anisotropic dispersal of pollen and seed will strongly influence mating patterns (e.g., correlated paternity), gene flow and spatial genetic structuring of neutral and adaptive genes. In the case of dispersal by animals, anisotropic patterns are generally related to the relative location of source trees, animal home ranges, and habitat, and can potentially be explained and reproduced by mechanistic models. In the case of dispersal by wind or water, anisotropy reflects the directionality of the dispersal vector, and/or asymmetries in the distribution of favorable deposition sites around the source. It is relatively straightforward to reproduce anisotropic patterns in mechanistic models of dispersal by wind or water, given data on the directionality of the dispersal vector [26]. However, most field studies of dispersal by wind simply integrate predictions and data over all directions [72]. This may in part reflect the challenge of describing anisotropic patterns with phenomenological models and the fact that anisotropic dispersal kernels invariably involve more parameters than isotropic ones and require larger samples to be fitted. Van Putten et al. [73] introduced a general framework for phenomenological anisotropic kernels that includes all previous such kernels (referenced in [73]) as special cases. Future research should better describe anisotropic dispersal patterns with available statistical tools, explain these patterns mechanistically, and evaluate their consequences for plant populations.

\section{How can we measure long-distance dispersal across plant species' ranges?}

Long-distance dispersal (LDD) can be defined in absolute terms as the fraction of dispersal events that occurs above a given threshold distance associated with the biology, demography and environment of the species [4]. LDD of seed and pollen is important to the speed of colonization or invasion, metapopulation dynamics, long-distance gene flow, local adaptation, adaptive evolution [74], and demographic and genetic effects of fragmentation [75]. Island colonization and dispersal biogeography studies have demonstrated the potential for effective plant dispersal over scales of hundreds to thousands of $\mathrm{km}$, and how understanding vector characteristics enable predictions about long-distance plant migration routes over extended time periods (e.g., [76,77]). Future studies on this front should build on more explicit mechanistic models of the interaction between vectors and propagule traits (see Section 1), and account for species' establishment niches and potential arrival habitats, to provide a sounder hypothesis-testing framework concerning the source, path and effective establishment sites of long-distance propagules [78]. Dispersal biogeography approaches are limited in that they are difficult to apply within continents and cannot generally estimate dispersal rates [79]. Tallying the arrival of different gene lineages into islands may shed more light on the frequency and origin of LDD [80], but this approach only provides minimum frequency estimates, because immigrant lineages may have gone extinct through competition, drift or selection.

More general models are available to infer historical (i.e., averaged over generations) seed- and pollen-mediated gene dispersal rates among discrete populations using genetic structure data. These methods rely on simple demographic history assumptions to separate the genetic signature of dispersal from those of random drift and shared ancestral polymorphism $[81,82]$. Their spatial scale of analysis is potentially large, making them suitable for historical LDD inference, with the caveats that model misspecification and unsampled populations can bias dispersal estimates $[83,84]$, and that current and past population distributions need not coincide, which complicates inferring the actual scale of dispersal estimates. In the case of continuously distributed species, theoretical studies have 
predicted how different LDD levels during range expansion should be reflected in contrasting genetic structures across newly colonized areas [85-90], but we still lack formal methods to use this kind of information. Future methodological advances will surely exploit the flexibility of Approximate Bayesian Computation (ABC) methods for LDD inference from genetic structure data under realistic demographic assumptions, both for discrete and continuous populations e.g. [91,92], as well as the information about gene flow contained in linkagedisequilibrium patterns across whole genomes [93]. Efforts to adapt these tools to disentangle the relative contribution of seed versus pollen dispersal to historical gene flow rates, either with uni- or biparentally inherited markers, would be a welcome addition for plant ecologists, as this topic has remained notably underexplored since the basic island model in [94] and [95].

Although historical LDD is interesting for biogeographic, population genetic and evolutionary studies, broad-scale patterns of dispersal under current (non-equilibrium) demographic and environmental conditions are becoming of greater concern. We anticipate growing emphasis on contemporary dispersal research spanning increasingly larger scales, using spatially and environmentally explicit approaches, and distinguishing effective dispersal (leading to successful establishment or reproduction) from basic dispersal (encompassing only propagule movement from source to deposition sites) [96]. Tracking recent or ongoing range expansions will remain a reliable source of information about the range of effective dispersal and the speed of migration into new habitats [97,98], while offering methodological advantages to establish recent LDD contributions to population establishment and growth [99]. A more general problem will be to estimate contemporary seed and pollen dispersal rates between discrete populations, or between localities throughout continuous plant ranges, accounting for or jointly inferring the effect of relevant spatial, demographic and environmental factors determining basic and effective dispersal. Mechanistic models provide a good basis for this purpose, but they are hard to validate over broad distances and do not easily reflect post-dispersal processes leading to effective dispersal $[74,96]$. Genetic methods are harder to extrapolate beyond the sampling area, but they can provide data at multiple spatial scales to validate mechanistic predictions, and estimate either basic or effective propagule dispersal with appropriate choice of sampling protocols and statistical analyses [96,100]. This flexibility of genetic methods can be exploited to investigate processes operating between the dispersed-seed and established-seedling (or between the dispersed-pollen and viable-embryo) stages, which increase spatiotemporal variation in effective dispersal patterns (see Sections 4, 5 and 7). Overall, scaling up mechanistic or genetic methods alone is unlikely to succeed for estimating contemporary seed and pollen dispersal rates (either basic or effective) over broad scales [74], so we suggest combining both.

The combination of mechanistic and genetic methods could be formalized within an 'inverse problem' framework: parameter estimates of the underlying mechanisms are retrieved from the (noisy) observation of resulting spatial patterns through mechanistic-statistical models [101] or state-space models [64], which associate a mechanistic model for the biological processes of interest to a statistical model for the observations. Inverse methods are increasingly popular for investigating large-scale biological mechanisms in general [102], and particle dispersion from unknown sources in particular [103], thanks to increasing computational power and the development of numerically intensive statistical methods (Bayesian MCMC, ABC). Concerning the statistical "component" of our problem of dispersal among discrete populations, genetic assignment methods (reviewed in [104]) are an appealing choice, because they overcome substantially the spatial scale limitation of genetic parentage analysis. Moreover, some developments of these methods explicitly estimate recent migration rates among populations [105-107], and specifically seed (or seedling) and pollen migration rates [108-110], defined as the proportion of propagules immigrating into a population. These procedures easily admit the incorporation of mechanistic formulations of seed and pollen migration rates (see Additional file 1), thus moving from the estimation of seed and pollen migration rates themselves to the estimation of the parameters of a mechanistic model for these rates [106,111].

For wind-dispersed propagules, mechanistic models for among-population migration rates could embed regional wind data in the form of connectivity maps, describing the probability of basic seed or pollen dispersal along possible trajectories linking a set of locations $[77,112]$, as well as sub-models for propagule mortality during transport [72,113], mortality between seed deposition and seedling establishment for effective seed dispersal [114], and flowering phenological synchrony [115] and cross-population pollination rates [116] for effective pollen dispersal. Considering animal-driven seed or pollen dispersal in spatially heterogeneous landscapes, the mechanistic component for the connectivity network could build upon previous work on diffusive movement in patchy populations or metapopulations [64]. Some simple movement behavioral models indeed enable the analytical derivation of pairwise migration rates considering the structure of the entire landscape and not only the two populations considered (e.g. $[117,118]$ ), while new automated track annotation systems can help calibrate such behavioral models [60] (see also Section 2). Additional submodels would be necessary to include the pollen carry-over by individual pollinators or retention time of individual 
seed-dispersers, which may be particularly important for LDD events over continental scales [119]. In mosaic landscapes, the use of resistance surfaces to build connectivity maps (using least-cost distances, ecological distances or resistance distances) is also a promising approach [120]. This approach focuses extensively on the effect of land-use on dispersal, but methods are still needed to reliably parameterize the resistance values $[120,121]$. Finally, several types of observations resulting from the same processes could be analyzed simultaneously using mechanistic-statistical modeling, especially when associated with hierarchical Bayesian statistics [122]. Future studies should thus take this opportunity to estimate process parameters not only from genetic data but also from demographic, capture-recapture or presenceabsence data $[123,124]$. The complexity of models including all these elements and the challenge of obtaining ecological data to parameterize them may be daunting, but we have reached the point where sufficient knowledge about the separate elements is available to attempt a multidisciplinary integration into useful inferential and predictive frameworks.

This combined genetic-mechanistic framework might also be applied to continuously distributed species, provided genetic assignment remained feasible. If significant clinal genetic variation were present over the spatial scale of the dispersal study, genotypic probabilities for dispersed propagules at any given location could be expressed as a continuous function of distance along the allele-frequency cline, potentially enabling the estimation of the LDD component along this direction. In the case of non-clinal (patchy) spatial genetic structure, allele frequency smoothing techniques may allow genetic assignment of propagules to a set of sampled and unsampled sources across the species range $[125,126]$, although the accuracy of this method under contrasting sampling, dispersal, and genetic structure scenarios remains to be tested. If the number of migrant propagules is large (unfortunately an unlikely case for LDD), it may also be possible to use the genotypic composition of the propagule sample to help infer propagule migration rates from a known [127] or unknown [128] number of unsampled locations.

\section{How variable are dispersal kernels among individuals and populations and what are the most important factors contributing to this variation?}

Plant dispersal kernels are expected to be phenotype- and environment-dependent, given the number of intrinsic and extrinsic variables influencing the release, transport and settlement of seeds and pollen. Less evident is the relative weight of each variable, and how dispersal kernel variation is hierarchically distributed across individuals, populations and species, as well as over time. We deal with temporal dispersal variation in Section 5, and focus here on interindividual and interpopulation variation in dispersal kernels. Among-species variation in multivariate phenotypes putatively associated with dispersal (dispersal 'syndromes') can be substantial, and is usually interpreted in terms of vector specialization, resulting in potentially large differences in propagule dispersal kernels $[7-9,129,130]$. However, intraspecific variation has been shown to be as large as or even larger than interspecific variation for particular dispersal traits of some animal species, as a consequence of genetic variation among and within populations and of individual phenotypic plasticity [131]. Although analogous hierarchical quantitative analyses are still missing in plants, similar results could be anticipated, because substantially different seed and pollen dispersal estimates have been obtained among populations with contrasting density, parental architecture, and vector characteristics, both for wind- and animal-mediated dispersal [132-137]. Further comparative studies of propagule dispersal in multiple sites and populations would be advisable to overcome common methodological limitations in previous studies, such as unbalanced sampling designs, narrow spatial and temporal sampling scales, poor or absent uncertainty assessment of the difference in dispersal estimates (but see [138]), and insufficient or null replication across sites differing in intrinsic or extrinsic factors of interest. It will then be possible to move from the mere assessment of dispersal variation towards a hypothesis-driven identification of its environmental, demographic and phenotypic determinants. For this purpose, it would be advisable to combine empirical measurements of dispersal kernel parameters with mechanistic predictions based on measurements of vector occurrence and characteristics, environmental variables, and plant dispersal traits, along the principles suggested in Section 1.

At a narrower spatial scale, dispersal kernel variation within populations is primarily caused by local-scale heterogeneity in phenotypic dispersal traits and/or by the effects of local environmental variation on dispersal vectors (e.g., wind and frugivore behavior, Section 2) $[42,54,56,139,140]$. Changes in dispersal distances should also be expected among individuals with different pollen shedding or seed release phenology, if the different vector contributions and/or behaviors vary throughout the season [141,142]. In addition, differences in microhabitat, age, and genotype may produce variation in parental (e.g. plant height) and propagule (e.g. fruit or seed size) phenotypic traits associated with dispersal [143-145]. However, dispersal kernels are generally considered constant within populations, probably because this is assumed by statistical approaches typically used to fit observed patterns of dispersal $[15,18,19,35]$. Future models could attempt to estimate the within-population distribution of dispersal kernel parameters and their association with local phenotypic 
and environmental variables, using either mechanistic approaches [41] or extensions of recently developed genetic methods to estimate individual variation in dispersal parameters [146,147]. The latter methods could also estimate the association between dispersal kernel parameters and reproductive success, which, to the extent allowed by sampling and spatial scale limitations, would start shedding light on the individual fitness consequences of shortand long-distance dispersal in particular environments. Estimates of individual variation in dispersal kernel parameters could also be combined with quantitative genetics methods to estimate heritability in the wild [148], as a first step to evaluate the genetic determinism of dispersal traits.

Gathering empirical information about intraspecific variation in seed and pollen dispersal kernels and its phenotypic and environmental drivers will contribute to the construction of more realistic models of species distribution and interactions in changing environments (see Sections 6, 7 and 8), while determining what proportion of this variation is genetically determined will be essential for assessing the potential for evolution of dispersal in future environments [149]. There are a few welldocumented cases of rapid seed dispersal evolution during colonization [150-154] and after habitat fragmentation $[155,156]$, but these evolutionary responses will probably be highly variable across taxa, owing to differences in standing genetic variation, trait heritability, phenotypic plasticity and fitness effects of dispersal traits [157]. Important insights could be obtained from phenotyping individual dispersal traits and dispersal kernels in common garden experiments replicated in contrasting environments [158]. In conducting these experiments, it would be ideal to (i) measure the short- and long-distance components of seed and pollen dispersal kernels and their presumed phenotypic and environmental correlates; and (ii) assess potential correlations between dispersal and other phenotypic traits of ecological relevance, which might represent multivariate genetic constraints on dispersal evolution [159].

\section{How temporally variable is dispersal and what are the implications of this variation for plant populations and communities?}

Dispersal varies not only over spatial scales (see Sections 2 and 4), but also over time scales, from seconds to weeks to years, due to temporal variation in endogenous and exogenous factors influencing dispersal. Wind speed and direction, including wind turbulence, vary temporally due to both variable atmospheric forcing and varying local leaf area density, vegetation structure, and landscape configuration $[10,141]$. Pollinator and frugivore guild composition, abundance, and behavior also vary temporally $[142,160,161]$, with behavior influenced especially by the local abundance and spatial distribution of other flowering and fruiting plants $[162,163]$. There is also temporal variation in the physical condition and form of the diaspore and of tissues involved in seed release or abscission in wind-dispersed species [164], or in plant traits that attract and reward animal dispersers $[165,166]$.

Most dispersal studies disregard this temporal variability, yet it critically affects the interpretation of dispersal data. Because of temporal variation, sampling duration and timing can strongly affect dispersal estimates [167]. The standard approach is to implicitly average over temporal variability, providing time-integrated measures of dispersal over the season or seasons of study (e.g. [168]). The few studies that have evaluated dispersal in multiple seasons or years have found significant temporal variation, for both pollen [169] and seeds [36,170]. This calls into question our ability to draw conclusions about dispersal in systems in which data collection spans only one or a few seasons or years, as is the case in the vast majority of empirical dispersal studies.

Temporal variation in dispersal has important implications for plant populations. Inter-annual variation in pollen and seed dispersal can determine mating system variation [169], the assemblage of genetic diversity during regeneration [171] and the heritability and the response to selection of dispersal-related traits [149]. This is especially relevant for long-lived species, where the contribution of individuals to population demography and genetics spans over multiple reproductive and dispersal episodes [172]. Knowing the extent of temporal variation in dispersal could also shed more light on the consequences of masting for population dynamics, because masting benefits could be influenced by temporal covariation between seed crop size and spatial patterns of seed dispersal, a potential association that remains largely unexplored (but see [173]). More generally, establishing temporal covariation patterns between environmental variables, reproductive rates, seed and pollen dispersal patterns, and effective seedling establishment rates will shed light on the frequency of the rare favorable years on which successful recruitment of long-lived species may disproportionately depend [174], and their effect on the evolution of pollination and dispersal strategies, the speed of population migration under climate change (see Section 7) and the spread of invasive species $[175,176]$.

We thus advocate and expect more studies measuring temporal variation in seed and pollen dispersal, its mechanistic determinants, and its consequences for populations and communities, much as we have advocated for studies of spatial variation in dispersal (Section 4). Temporal characterizations of seed and pollen dispersal should go beyond measuring variation in fecundity to examine fluctuations in dispersal distances and landscape-dependent dispersal patterns (Section 2), and their association with focal plant 
conditions and vector dynamics. The task can be enormous when dealing with complex ecological networks or large landscapes; a comprehensive understanding of temporal variation in dispersal will probably require conceptual and methodological advances to establish a clear partition of dispersal variability into environmental, spatial and temporal components (see [169] for a comparable scheme applied to mating systems) over different nested scales.

Insofar as temporal variation in seed dispersal is an important contributor to temporal variation in recruitment success, it also becomes a critical component of studies of community dynamics, and specifically the potential for species coexistence via temporal niche differentiation, also known as the "storage effect" [177]. In this context, a critical question concerns the degree to which temporal variation in seed dispersal is synchronous or asynchronous among species. Temporal fluctuations in wind speed or frugivore abundance might be expected to lead to synchronous variation, while competition for shared frugivores could lead to asynchronous variation [161]. Studies are needed to evaluate the consequences and importance of temporal dispersal variation at multiple scales for plant communities. In particular, long-term multi-species studies should investigate how coexisting species co-vary in their temporal patterns of seed dispersal, and quantify associated contributions to interspecific patterns of temporal variation in recruitment. To address these multi-species questions, much is expected from advances in the spatial analysis of plant-plant and plants-frugivore networks [140] that incorporate demographic and genetic aspects of focal species or populations $[178,179]$.

\section{What is the actual importance of seed dispersal in determining community processes and patterns?}

Seed dispersal is one of four fundamental processes in community ecology, the others being selection (deterministic differences in per capita growth rates among species), drift (stochastic changes in species abundances), and speciation [180]. The importance of seed dispersal for community patterns of species diversity, abundance, and composition is generally accepted; indeed, it is often stated in introductions and discussions of empirical studies of dispersal. Further, theoretical studies clearly show that seed dispersal or migration rates strongly influence community patterns in neutral and niche models (e.g., $[181,182])$. However, there is a scarcity of empirical studies convincingly demonstrating the role of seed dispersal rates and patterns for community dynamics and structure [183].

Several types of empirical studies to date have provided insights into the role of seed dispersal in community patterns, but each has major shortcomings. Empirical analyses of species turnover in space (beta diversity) often invoke seed dispersal as the explanation for distance-dependent patterns not explained by environmental variation (e.g., [184]); however, these studies are inherently limited in their ability to distinguish the influence of dispersal from that of environmental niches [185], do not consider distanceindependent variation in dispersal, and generally include no link to empirically measured dispersal (but see [186]). Empirical studies of variation in community patterns with differences in isolation/connectivity and hence presumed seed dispersal/migration rates generally find strong relationships, but these studies usually have important confounding factors - e.g., differences in the abundance and species composition of animals that interact with plants [187] or in the quality of habitat patches [188]. Studies comparing areas with and without vertebrate seed dispersers, whether due to differences in hunting pressure or to experimental exclusion, are similarly confounded by variation in vertebrate seed predation and herbivory $[189,190]$. Numerous experimental seed addition studies have shown that species diversity and composition often responds strongly to seed availability - but these studies effectively simulate alterations in fecundity as much as or more than they do dispersal [191].

The lack of good empirical tests of theory on the importance of seed dispersal to communities in part reflects a mismatch between the simplistic way in which dispersal is generally represented in models and the more complex dispersal patterns observed in most real ecosystems. Most models set seed dispersal rates as identical for all species, when in the real world dispersal rates invariably vary greatly among species within communities. Further, a common approach is to model seed dispersal as a dichotomy of within-patch vs. between-patch dispersal using a metacommunity framework $[192,193]$. Few realworld ecosystems are well-approximated by such models, especially when all patches are assumed equally connected, as is generally the case. The alternative is spatially explicit models of communities. Advances in computing and in mathematical techniques, particularly moment methods, have made these models increasingly accessible and tractable, and has led to a tremendous increase in relevant theoretical work [194-197]. This work has expanded our understanding of how seed dispersal can affect community patterns in theory, both alone and in interaction with selection and drift.

We believe that two alternative approaches offer the best potential to advance our understanding of the role of seed dispersal in community patterns - not only spatial patterns of turnover, but also relative abundances, species composition, and diversity. The first is large-scale field experiments manipulating dispersal patterns. Such manipulations should involve not only seed addition, but seed redistribution within areas of study. These might for 
example involve extending or restricting seed dispersal for all species, and/or homogenizing seed dispersal patterns across species. Few seed redistribution studies have been undertaken even for individual species at small scales [198], much less communities. The second approach is to adroitly combine empirical and theoretical work, by collecting empirical data on seed dispersal and competitive interactions for multiple species sufficient to parameterize simulation models that reproduce relevant community patterns, and then using these models to conduct simulation experiments regarding the effects of altered seed dispersal on community patterns. For example, Ribbens et al. [15] and Pacala et al. [199] take such an approach to examine the importance of seed dispersal to a temperate forest community, parameterizing the spatially explicit, individual-based model SORTIE, and then evaluating the sensitivity of species relative abundance and other community patterns to changes in dispersal parameters. More studies of these kinds are needed to establish how seed dispersal matters not only to populations, but to communities.

\section{How will dispersal influence population viability under climate change?}

We now take a long-term perspective to examine the importance of seed and pollen dispersal in the complex interaction between demographic dynamics and adaptive processes in a changing climate. A more conventional title for this section could have run "Will plants migrate fast enough to avoid extinction under climate change?", but this potentially misleading question suggests that tracking suitable habitats through migration is the only mechanism by which plants can avoid extinction in a dynamic environment, disregarding genetic adaptation and adaptive phenotypic plasticity. Paleoecological records, especially rich for woody plants, suggest that latitudinal and altitudinal displacements from multiple refugial sources have been the main responses of many plant species to past climate changes [200-202], but migration probably has interacted and will interact with genetic evolution, gene flow and phenotypic plasticity. For instance, climatic tolerance and dispersal capacity can both evolve during migration [74,203,204], effective pollen or seed dispersal among distant populations may favor adaptation to new conditions [74,205], and adaptive phenotypic plasticity may buy time for migration, as it buffers the demographic effects of maladaptation [206]. A more relevant question would thus be whether the joint action of dispersal, genetic evolution and phenotypic plasticity will be sufficient to avoid the extinction of particular populations under the novel selective pressures brought by climate change, given population-specific factors such as census and effective size, current climatic tolerance, interspecific interactions [207], geographic range position [208], landscape connectivity [209], gene immigration from other populations [74], levels of standing multivariate genetic variance [210], and multivariate genetic constraints to adaptive evolution $[159,211]$. Even if we will probably see the consequences of climate change before being able to answer such a question, it remains relevant to rank populations according to estimated extinction risk, and to identify the main natural and anthropogenic factors reducing their viability, including dispersal limitation.

Efforts to incorporate this complexity in the prediction of climate-driven species range shifts are heading to the combination of simple habitat models with mechanistic spatially-explicit models of metapopulation dynamics [212-215], genetic and phenotypic adaptation [208,216, 217], and species interactions [218,219]. Future work should deal with knowledge gaps that are critical for linking the different components of these models, such as the effects that long-distance seed and pollen dispersal (along with genetic adaptation and phenotypic plasticity) have on population fitness and demographic dynamics, as well as the potential feedbacks between demographic, ecological and evolutionary processes [206,207,220-223]. Plant movement ecologists can make important contributions to this multidisciplinary endeavor by formulating and fitting realistic individual and gene movement modules that are interactive with the ecological and demographic layers of range-shift models. Rather than assuming invariant migration, population spread models should use mechanistic descriptions of seed fecundity, transport and establishment, enabling the integration of relevant phenotypic, climatic, and ecological factors that determine variation in the seed dispersal kernel (see Sections 1, 2, 4 and 5). Recent works have weighed the relative effects of some of these factors on plant population spread, including seed and maternal plant morphology, wind conditions, non-random seed abscission, animal movement and seed retention time, seed fecundity, plant maturation age, plant longevity, and environmentdependent post-dispersal mortality [37,224-229]. From these studies, it is becoming clear that post-dispersal factors determining effective establishment and growth are as important or more than long-distance seed transport in determining the speed of plant migration. We therefore need not only better LDD data, but also further studies to characterize niche variation across plant life stages, from seed germination, through seedling establishment, to adult survival and reproduction [230233]. We will then be in a better position to understand how the interplay between LDD, niche requirements, and dynamic heterogeneous environments (including fragmented habitats with variable abundance of mates, dispersers, predators and competitors) determines the speed of spread of plant populations under climate change. 
Species distribution models allowing for genetic evolution should also include realistic modelling of seed- and pollen-mediated gene flow among populations across shifting ranges, since both are expected to influence local adaptation and niche evolution [74,223]. In Section 2 we outlined a mechanistic framework for modelling seed and pollen migration rates among populations that would be amenable to integration into future broad-scale species distribution models, because it can account for spatial, demographic, and environmental determinants of longdistance propagule transport probabilities, and can be fitted empirically using genetic marker information. It would thus be possible to obtain a measure of the regional ecological neighborhood to which a focal population is exposed through gene immigration (similarly to [234], but weighted by contemporary propagule transport probabilities). The ecological and genetic layers of the model could then determine the probability of establishment of seed immigrants or hybrids and their potential population fitness consequences, conditioned on the habitats of origin and arrival and the species niche across life-stages. Ultimately, any quantitative prediction about population viability will be sensitive not only to model selection but also to the choice of parameter values. Future transplant and controlled-pollination experiments should help us quantify the probability of effective establishment for longdistance seed and pollen migrants under varied biotic and abiotic environments [235].

\section{Will dispersal across anthropogenic landscapes in a globalized world be limited or enhanced?}

Human activities have become a key driver of plant dispersal, both through their direct contribution to the transport of propagules (e.g., [236,237]) and through anthropogenic changes in land use, habitat fragmentation, biotic connectivity (resulting in biological invasions) and climate change $[238,239]$. All these factors represent important global drivers of genetic erosion, species extinction and biodiversity loss [240,241]; hence, understanding their combined impact on seed and pollen dispersal represents a challenging but tremendously important task. In turn, increasing our current understanding of plant dispersal has been identified as a critical factor to obtaining reliable prediction of plant responses to global environmental change (GEC hereafter) (see Section 7 and [242,243]).

The prospects are particularly worrying for animalmediated pollen and seed dispersal, because plant-animal mutualisms tend to be negatively affected by most drivers of GEC [244]. For example, habitat fragmentation, biological invasions and climate change negatively affect outcross pollination and mating patterns of insectpollinated species (reviewed in [245] and [246]). Cascading effects of reduced pollination on seed dispersal by animals could be exacerbated by direct effects of climate on fruiting phenology [247], the disruption of seeddispersal mutualisms by invasive species [248] and impaired dispersal among habitat fragments [249]. Effective seed dispersal may be reduced further by associated increases in seed and seedling predation (e.g., [250]). These effects vary among plant species, depending in part on their morphological or functional traits. For example, large-seeded species tend to show stronger reductions in seed dispersal and stronger decreases in seed predation as a result of fragmentation (e.g., [251,252]), largely owing to the defaunation of smaller fragments (i.e., the selective removal of large-bodied dispersers and predators; e.g. [253,254]).

Generalizing the effects of multiple drivers of GEC on communities is challenging, because communities are interlinked by interactions of variable sign and strength, and because these effects are likely to be scale- and species-dependent (e.g., [255] for the response of pollinators to land use changes). This task will probably require a "patchwork" of approaches, including (i) correlational landscape-level approaches to infer relationships between drivers and response variables and determine how they scale over space and time; (ii) comparative studies that identify adequate predictors of species' responses to GEC based on morphological, behavioral and functional traits, and estimate their effects on species interactions and interaction networks; (iii) mechanistic studies based on detailed information of representative systems, in which seed dispersal models based on individual, rule-based descriptions of animal movement are used to generate scenarios of broader-scale responses to GEC (see Sections 2 and 7); and (iv) experimental manipulations of fragmented and/or anthropogenic landscapes (e.g., patch characteristics, habitat corridors or landscape features influencing matrix permeability [256-259]) to test predictions regarding planned landscape modifications undertaken for management purposes (using, whenever possible, an adaptive approach; [260,261]). The combination of these four approaches could provide more accurate estimates of the responses to anthropogenic pressures acting on different species assemblages, for various spatial arrangements, management regimes and temporal scales.

On first principles, the effects of GEC on windmediated pollen and seed dispersal should be more straightforward [262]. Empirical results and theoretical predictions suggest however that this is not necessarily the case, because some fragmented plant populations exhibit enhanced wind dispersal of seed and pollen while others show the reverse trend [75], and because different assumptions about future wind speeds lead to opposite airborne propagule dispersal predictions $[225,228,263]$. It is clear that variation in wind-mediated dispersal mechanisms should determine interspecific differences in dispersal sensitivity to habitat alteration 
and climate change, but some of the conflicting results in the literature seem to be the consequence of (i) a poor characterization of habitat and demographic disturbance over relevant spatial scales, relative to seed or pollen dispersal range, and (ii) high uncertainty about future local and regional wind regimes, two issues that deserve more careful attention. Efforts to predict the effects of GEC on wind dispersal are especially hampered by the difficulty of modeling LDD (see Section 3 ) and its interaction with the spatiotemporal variability that often characterizes anthropogenic landscapes (e.g., [264]). Long-distance wind dispersal of plant propagules depends on phenomena, such as turbulent updrafts and downdrafts, that vary strongly with local and regional weather conditions, micro-topography, foliage density, and canopy and habitat structure $[3,10,11,46,265]$. Predictions are certainly aided by the increasing refinement of mechanistic models $[40,72,225,227,265,266]$, but these need to be better validated if low frequency events are to be reliably predicted. The integration of genetic and mechanistic models bears the strongest potential for this task (Section 3). On the other hand, extrapolation of model predictions across species or functional types can be used to derive approximate generalizations about vegetation responses to GEC (e.g., [7-9,130]), which should be tested using correlative studies and experimental manipulations in real landscapes (as advocated above for animal-mediated dispersal).

Applications of this knowledge to the management of anthropogenic landscapes must factor in the potential consequences of pollen and seed dispersal across such altered landscapes - consequences that may be positive or negative overall $[267,268]$. Gene flow tends to increase genetic variation within populations, limiting inbreeding depression and increasing evolutionary potential, but it may also limit local adaptation owing to introgression of maladapted genes and the disruption of co-adapted gene complexes [269-272]. A comparable duality of effect may be expected at the community level, with increased connectivity enhancing local population persistence and alpha diversity - but tending also to increase homogenization (reducing beta diversity) and facilitate the arrival of invasive species, pathogens and parasites [273-276]. This is particularly important in current scenarios of rapid climate change, in which habitat fragmentation and the establishment of foreign genotypes and species may constrain the processes of local adaptation and geographic redistribution required for species and community persistence [268]. The evolving metacommunity framework provides a sound theoretical ground for advancing estimates on the optimal levels of connectivity in anthropogenic landscapes subjected to GEC (e.g., [277]), which could be validated and refined using management actions aimed at enhancing connectivity.

\section{Conclusions}

Advances in plant dispersal ecology research will be determined by our ability to surmount challenges of spatial scale and heterogeneity, temporal scale, and system complexity. Enlarging the spatial scale of empirical studies will remain a necessity to avoid biased descriptions of dispersal and its ecological and evolutionary consequences. New inferential and predictive schemes should be developed and applied to better describe the rate and trajectories of effective seed and pollen migrants over different spatial scales in environmentally and demographically explicit context, incorporating landscape-dependent components of vector and propagule movements. This will probably require a combination of mechanistic and phenomenological (e.g., genetic-based) approaches that, in the unavoidable trade-off between spatial scope, sampling intensity and accuracy, should seriously assess expected statistical power and uncertainty for low-frequency (but still ecologically and evolutionarily important) dispersal rates, model miss-specifications, and limited sampling. Temporal scale issues will pervade plant dispersal ecology studies, from a more meaningful characterization of average dispersal patterns given variation in dispersal within and among seasons, through the assessment of the consequences of such temporal dispersal variation for population and community dynamics, to long-term predictions about population and species persistence based on observed and modelled feedbacks between dispersal, demography and evolution in changing environments. Finally, sufficiently approximating the dynamic complexity of environments, ecological networks and communities will be essential for characterizing all relevant biotic and abiotic mechanisms driving plant dispersal and their sensitivity to global change, and for better understanding the ecological consequences of dispersal in changing environments. We will certainly need to increasingly pool data and expertise from multiple disciplines to meet these big challenges, for which we advocate not only further cooperative research efforts, but also the implementation, standardization and usage of open repositories of dispersal data and models.

\section{Additional file}

Additional file 1: Combining genetic and mechanistic approaches for long-distance dispersal estimation.

\section{Abbreviations}

ABC: Approximate Bayesian computation; GEC: Global environmental change; LDD: Long-distance dispersal.

\section{Competing interests}

The authors declare that they have no competing interests. 


\section{Authors' contributions}

JJRA conceived and led the study. All authors contributed research ideas and participated in manuscript writing. All authors read and approved the final manuscript.

\section{Acknowledgements}

This work was partly supported by CGL2009-09428 project from the Spanish Ministry of Economy and Competitiveness. We thank Pedro Jordano and two anonymous reviewers for constructive comments.

\section{Author details}

${ }^{1}$ Department of Forest Ecology \& Genetics, INIA-CIFOR, Ctra. de la Coruña km 7.5, 28040 Madrid, Spain. ${ }^{2}$ INRA, UR546 Biostatistique et Processus Spatiaux (BioSP), Avignon, France. ${ }^{3}$ Smithsonian Tropical Research Institute, Apartado Postal 0843-03092 Panamá, Republica de Panamá. ${ }^{4}$ Spatial Ecology Group, Doñana Biological Station (EBD-CSIC), Sevilla, Spain.

Received: 5 May 2014 Accepted: 24 July 2014

Published: 1 August 2014

\section{References}

1. Clobert J, Baguette M, Benton TG, Bullock JM (Eds): Dispersal Ecology and Evolution. Oxford: Oxford University Press; 2012.

2. Cousens R, Dytham C, Law R: Dispersal in Plants: A Population Perspective. Oxford: Oxford University Press; 2008.

3. Higgins SI, Nathan R, Cain ML: Are long-distance dispersal events in plants usually caused by nonstandard means of dispersal? Ecology 2003, 84:1945-1956.

4. Nathan R, Schurr FM, Spiegel O, Steinitz O, Trakhtenbrot A, Tsoar A: Mechanisms of long-distance seed dispersal. Trends Ecol Evol 2008, 23:638-647.

5. Culley TM, Weller SG, Sakai AK: The evolution of wind pollination in angiosperms. Trends Ecol Evol 2002, 17:361-369.

6. Bascompte J, Jordano P: Plant-animal mutualistic networks: the architecture of biodiversity. Annu Rev Ecol Evol Syst 2007, 38:567-593.

7. Vittoz P, Engler R: Seed dispersal distances: a typology based on dispersal modes and plant traits. Bot Helv 2007, 117:109-124.

8. Thomson FJ, Moles AT, Auld TD, Ramp D, Ren S, Kingsford RT: Chasing the unknown: predicting seed dispersal mechanisms from plant traits. J Ecol 2010, 98:1310-1318.

9. Tamme R, Götzenberger L, Zobel M, Bullock JM, Hooftman DAP, Kaasik A Partel M: Predicting species' maximum dispersal distances from simple plant traits. Ecology 2014, 95:505-513.

10. Nathan R, Katul GG: Foliage shedding in deciduous forests lifts up long-distance seed dispersal by wind. Proc Natl Acad Sci U S A 2005 102:8251-8256

11. Nathan R: Long-distance dispersal of plants. Science 2006, 313:786-788

12. Siljamo P, Sofiev M, Severova E, Ranta H, Kukkonen J, Polevova S, Kubin E, Minin A: Sources, impact and exchange of early-spring birch pollen in the Moscow region and Finland. Aerobiologia (Bologna) 2008, 24:211-230.

13. Varis S, Pakkanen A, Galofré A, Pulkkinen P: The extent of south-north pollen transfer in Finnish Scots pine. Silva Fenn 2009, 43:717-726.

14. Bullock JM, Clarke RT: Long distance seed dispersal: measuring and modelling the tail of the curve. Oecologia 2000, 124:506-521.

15. Ribbens E, Silander JA, Pacala SW: Seedling recruitment in forests: Calibrating models to predict patterns of tree seedling dispersion. Ecology 1994, 75:1794-1806.

16. Tufto J, Engen S, Hindar K: Stochastic dispersal processes in plant populations. Theor Popul Biol 1997, 52:16-26.

17. Klein EK, Lavigne C, Foueillassar X, Gouyon P-H, Larédo C: Corn pollen dispersal: quasi-mechanistic models and field experiments. Ecol Monogr 2003, 73:131-150.

18. Robledo-Arnuncio JJ, Garcia C: Estimation of the seed dispersal kernel from exact identification of source plants. Mol Ecol 2007, 16:5098-5109.

19. Jones FA, Muller-Landau HC: Measuring long-distance seed dispersal in complex natural environments: an evaluation and integration of classical and genetic methods. J Ecol 2008, 96:642-652.

20. Jordano P, García C, Godoy JA, García-Castaño JL: Differential contribution of frugivores to complex seed dispersal patterns. Proc Natl Acad Sci U S A 2007, 104:3278-3282.
21. Spiegel $O$, Nathan $R$ : Incorporating dispersal distance into the disperser effectiveness framework: frugivorous birds provide complementary dispersal to plants in a patchy environment. Ecol Lett 2007, 10:718-728.

22. Dennis AJ, Westcott DA: Estimating dispersal kernels produced by a diverse community of vertebrates. In Seed Dispersal: Theory and its Application in a Changing World. Edited by Dennis AJ, Schupp EW, Green RA, Westcott DA. Wallinford, UK: CABI Publ; 2007:201-228.

23. González-Varo JP, Arroyo JM, Jordano P: Who dispersed the seeds? The use of DNA barcoding in frugivory and seed dispersal studies. Methods Ecol Evol 2014, doi:10.111/2041-210X.12212.

24. Chifflet R, Klein EK, Lavigne C, Le Feon V, Ricroch AE, Lecomte J, Vaissiere BE: Spatial scale of insect-mediated pollen dispersal in oilseed rape in an open agricultural landscape. J Appl Ecol 2011, 48:689-696.

25. Nathan R, Sapir N, Trakhtenbrot A, Katul GG, Bohrer G, Otte M, Avissar R, Soons MB, Horn HS, Wikelski M, Levin SA: Long-distance biological transport processes through the air: can nature's complexity be unfolded in silico? Divers Distrib 2005, 11:131-137.

26. Nathan R, Safriel UN, Noy-Meir I: Field validation and sensitivity analysis of a mechanistic model for tree seed dispersal by wind. Ecology 2001 82:374-388

27. Andersen M: Mechanistic models for the seed shadows of wind-dispersed plants. Am Nat 1991, 137:476-497.

28. Greene DF, Johnson EA: A model of wind dispersal of winged or plumed seeds. Ecology 1989, 70:339-347.

29. Cresswell JE, Bassom AP, Bell SA, Collins SJ, Kelly TB: Predicted pollen dispersal by honey-bees and three species of bumble-bees foraging on oil-seed rape: a comparison of three models. Funct Ecol 1995, 9:829-841.

30. Soubeyrand S, Roques L, Coville J, Fayard J: Patchy patterns due to group dispersal. J Theor Biol 2011, 271:87-99.

31. Clark CJ, Poulsen JR, Bolker BM, Connor EF, Parker VT: Comparative seed shadows of bird-, monkey-, and wind-dispersed trees. Ecology 2005, 86:2684-2694

32. Wang BC, Smith TB: Closing the seed dispersal loop. Trends Ecol Evol 2002, 17:379-385

33. Levin SA, Muller-Landau HC, Nathan R, Chave J: The ecology and evolution of seed dispersal: a theoretical perspective. Annu Rev Ecol Syst 2003, 34:575-604.

34. Muller-Landau HC, Hardesty BD: Seed dispersal of woody plants in tropical forests: concepts, examples, and future directions. In Biotic Interactions in the Tropics: Their Role in the Maintenance of Species Diversity. Edited by Burslem DFRP, Pinard MA, Hartley S. Cambridge: Cambridge University Press; 2005:267-309.

35. Oddou-Muratorio S, Klein EK, Austerlitz F: Pollen flow in the wildservice tree, Sorbus torminalis (L.) Crantz. II. Pollen dispersal and heterogeneity in mating success inferred from parent - offspring analysis. Mol Ecol 2005, 14:4441-4452

36. Nathan R, Muller-Landau HC: Spatial patterns of seed dispersal, their determinants and consequences for recruitment. Trends Ecol Evol 2000, 15:278-285

37. Wright SJ, Trakhtenbrot A, Bohrer G, Detto M, Katul GG, Horvitz N, Muller-Landau HC, Jones FA, Nathan R: Understanding strategies for seed dispersal by wind under contrasting atmospheric conditions. Proc Natl Acad Sci U S A 2008, 105:19084-19089.

38. Hardy OJ, González-Martínez SC, Colas B, Fréville H, Mignot A, Olivieri I: Fine-scale genetic structure and gene dispersal in Centaurea corymbosa (Asteraceae). II. Correlated paternity within and among sibships. Genetics 2004, 168:1601-1614.

39. Wenny DG: Advantages of seed dispersal: a re-evaluation of directed dispersal. Evol Ecol Res 2001, 3:51-74.

40. Tackenberg O: Modeling long-distance dispersal of plant diaspores by wind. Ecol Monogr 2003, 73:173-189.

41. Santamaría L, Rodríguez-Pérez J, Larrinaga AR, Pias B: Predicting spatial patterns of plant recruitment using animal-displacement kernels. PLoS One 2007, 2:e1008.

42. Trakhtenbrot A, Katul GG, Nathan R: Mechanistic modeling of seed dispersal by wind over hilly terrain. Ecol Modell 2014, 274:29-40.

43. Murray KG: Avian seed dispersal of three neotropical gap-dependent plants. Ecol Monogr 1988, 58:271-298.

44. Puerta-Piñero C, Muller-Landau HC, Calderón O, Wright SJ: Seed arrival in tropical forest treefall gaps. Ecology 2013, 94:1552-1562. 
45. Kuparinen A: Mechanistic models for wind dispersal. Trends Plant Sci 2006, 11:296-301.

46. Bohrer G, Katul GG, Nathan R, Walko RL, Avissar R: Effects of canopy heterogeneity, seed abscission and inertia on wind-driven dispersal kernels of tree seeds. J Ecol 2008, 96:569-580

47. Pounden E, Greene DF, Quesada M, Contreras Sanchez JM: The effect of collisions with vegetation elements on the dispersal of winged and plumed seeds. J Ecol 2008, 96:591-598.

48. DiLeo MF, Siu JC, Rhodes MK, López-Villalobos A, Redwine A, Ksiazek K, Dyer RJ: The gravity of pollination: integrating at-site features into spatial analysis of contemporary pollen movement. Mol Ecol 2014 doi:10.1111/mec.12839.

49. Schurr FM, Bond WJ, Midgley GF, Higgins SI: A mechanistic model for secondary seed dispersal by wind and its experimental validation. J Ecol 2005, 93:1017-1028.

50. Rodríguez-Pérez J, Wiegand T, Santamaría L: Frugivore behavior determines plant distribution: a spatially explicit analysis of a plant-disperser interaction. Ecography (Cop) 2012, 35:113-123.

51. Cresswell JE, Osborne JL: The effect of patch size and separation on bumblebee foraging in oilseed rape: implications for gene flow. J App/ Ecol 2004, 41:539-546.

52. Vander Wall SB: Dispersal of singleleaf piñon pine (Pinus monophylla) by seed-caching rodents. J Mammal 1997, 78:181-191.

53. Pflüger FJ, Balkenhol N: A plea for simultaneously considering matrix quality and local environmental conditions when analysing landscape impacts on effective dispersal. Mol Ecol 2014, 23:2146-2156.

54. Schurr FM, Steinitz O, Nathan R: Plant fecundity and seed dispersal in spatially heterogeneous environments: models, mechanisms and estimation. J Ecol 2008, 96:628-641.

55. Morales JM, Carlo TA: The effects of plant distribution and frugivore density on the scale and shape of dispersal kernels. Ecology 2006 87:1489-1496.

56. Russo SE, Portnoy S, Augspurger CK: Incorporating animal behavior into seed dispersal models: implications for seed shadows. Ecology 2006, 87:3160-3174

57. Hickey J, Flynn R, Buskirk S, Gerow K, Willson M: An evaluation of a mammalian predator, Martes americana, as a disperser of seeds. Oikos 1999, 87:499-508.

58. Holbrook KM, Smith TB: Seed dispersal and movement patterns in two species of Ceratogymna hornbills in a West African tropical lowland forest. Oecologia 2000, 125:249-257.

59. Westcott DA, Bentrupperbaumer J, Bradford MG, McKeown A: Incorporating patterns of disperser behaviour into models of seed dispersal and its effects on estimated dispersal curves. Oecologia 2005, 146:57-67.

60. Dodge S, Bohrer G, Weinzierl R, Davidson SC, Kays R, Douglas D, Cruz S, Han J, Brandes D, Wikelski M: The environmental-data automated track annotation (Env-DATA) system: linking animal tracks with environmental data. Mov ECOl 2013, 1:3.

61. Guttal V, Bartumeus F, Hartvigsen G, Nevai A: Retention time variability as a mechanism for animal mediated long-distance dispersal. PLOS One 2011, 6:e28447.

62. Nathan R, Getz WM, Revilla E, Holyoak M, Kadmon R, Saltz D, Smouse PE: A movement ecology paradigm for unifying organismal movement research. Proc Natl Acad Sci U S A 2008, 105:19052-19059.

63. Côrtes MC, Uriarte M: Integrating frugivory and animal movement: a review of the evidence and implications for scaling seed dispersal. Biol Rev 2013, 88:255-272.

64. Patterson TA, Thomas L, Wilcox C, Ovaskainen O, Matthiopoulos J: State-space models of individual animal movement. Trends Ecol Evol 2008, 23:87-94.

65. Smouse PE, Focardi S, Moorcroft PR, Kie JG, Forester JD, Morales JM: Stochastic modelling of animal movement. Philos Trans $R$ Soc Lond B Biol Sci 2010, 365:2201-2211.

66. Levin DA, Kerster HW, Niedzlek M: Pollinator flight directionality and its effect on pollen flow. Evolution (N Y) 1971, 25:113-118.

67. Pyke $\mathrm{GH}$ : Optimal foraging: movement patterns of bumblebees between inflorescences. Theor Popul Biol 1978, 13:72-98.

68. Wagner S, Wälder K, Ribbens E, Zeibig A: Directionality in fruit dispersal models for anemochorous forest trees. Ecol Modell 2004, 179:487-498.

69. Austerlitz F, Dutech C, Smouse PE, Davis F, Sork VL: Estimating anisotropic pollen dispersal: a case study in Quercus lobata. Heredity (Edinb) 2007, 99:193-204.
70. Ahmed S, Compton SG, Butlin RK, Gilmartin PM: Wind-borne insects mediate directional pollen transfer between desert fig trees 160 kilometers apart. Proc Natl Acad Sci U S A 2009, 106:20342-20347.

71. Wälder K, Näther W, Wagner S: Improving inverse model fitting in trees-anisotropy, multiplicative effects, and Bayes estimation. Ecol Modell 2009, 220:1044-1053.

72. Katul GG, Porporato A, Nathan R, Siqueira M, Soons MB, Poggi D, Horn HS, Levin SA: Mechanistic analytical models for long-distance seed dispersal by wind. Am Nat 2005, 166:368-381.

73. Van Putten B, Visser MD, Muller-Landau HC, Jansen PA: Distorted-distance models for directional dispersal: a general framework with application to a wind-dispersed tree. Methods Ecol Evol 2012, 3:642-652.

74. Kremer A, Ronce O, Robledo-Arnuncio JJ, Guillaume F, Bohrer G, Nathan R, Bridle JR, Gomulkiewicz R, Klein EK, Ritland K, Kuparinen A, Gerber S, Schueler S: Long-distance gene flow and adaptation of forest trees to rapid climate change. Ecol Lett 2012, 15:378-392.

75. Kramer AT, Ison JL, Ashley MV, Howe HF: The paradox of forest fragmentation genetics. Conserv Biol 2008, 22:878-885.

76. Sauer JD: Plant Migration: The Dynamics of Geographic Patterning in Seed Plant Species. Berkeley and Los Angeles: University of California Press; 1988.

77. Muñoz J, Felicísimo AM, Cabezas F, Burgaz AR, Martínez I: Wind as a long-distance dispersal vehicle in the Southern Hemisphere. Science 2004, 304:1144-1147.

78. Gillespie RG, Baldwin BG, Waters JM, Fraser Cl, Nikula R, Roderick GK: Long-distance dispersal: a framework for hypothesis testing. Trends Ecol Evol 2012, 27:47-56.

79. Thornton IWB: Krakatau: The Destruction and Reassembly of an Island Ecosystem. Cambridge, Massachusetts: Harvard University Press; 1997

80. Alsos IG, Eidesen PB, Ehrich D, Skrede I, Westergaard K, Jacobsen GH Landvik JY, Taberlet P, Brochmann C: Frequent long-distance plant colonization in the changing Arctic. Science 2007, 316:1606-1609.

81. Beerli P, Felsenstein J: Maximum likelihood estimation of a migration matrix and effective population sizes in $n$ subpopulations by using a coalescent approach. Proc Natl Acad Sci U S A 2001, 98:4563-4568.

82. Nielsen R, Wakeley J: Distinguishing migration from isolation: a Markov chain Monte Carlo approach. Genetics 2001, 158:885-896.

83. Beerli P: Effect of unsampled populations on the estimation of population sizes and migration rates between sampled populations. Mol Ecol 2004, 13:827-836.

84. Slatkin M: Seeing ghosts: the effect of unsampled populations on migration rates estimated for sampled populations. Mol Ecol 2005, 14:67-73.

85. Nichols RA, Hewitt GM: The genetic consequences of long distance dispersal during colonization. Heredity (Edinb) 1994, 72:312-317.

86. Ibrahim KM, Nichols RA, Hewitt GM: Spatial patterns of genetic variation generated by different forms of dispersal during range expansion. Heredity (Edinb) 1996, 77:282-291.

87. Le Corre V, Machon N, Petit RJ, Kremer A: Colonization with long-distance seed dispersal and genetic structure of maternally inherited genes in forest trees: a simulation study. Genet Res 1997, 69:117-125.

88. Austerlitz F, Garnier-Géré P: Modelling the impact of colonisation on genetic diversity and differentiation of forest trees: interaction of life cycle, pollen flow and seed long-distance dispersal. Heredity (Edinb) 2003, 90:282-290.

89. Bialozyt R, Ziegenhagen B, Petit RJ: Contrasting effects of long distance seed dispersal on genetic diversity during range expansion. J Evol Biol 2006, 19:12-20.

90. Fayard J, Klein EK, Lefèvre F: Long distance dispersal and the fate of a gene from the colonization front. J Evol Biol 2009, 22:2171-2182.

91. Aeschbacher S, Futschik A, Beaumont MA: Approximate Bayesian computation for modular inference problems with many parameters: the example of migration rates. Mol Ecol 2013, 22:987-1002.

92. Ray N, Excoffier L: A first step towards inferring levels of long-distance dispersal during past expansions. Mol Ecol Resour 2010, 10:902-914.

93. Sousa V, Hey J: Understanding the origin of species with genome-scale data: modelling gene flow. Nat Rev Genet 2013, 14:404-414.

94. Petit RJ, Kremer A, Wagner DB: Finite island model for organelle and nuclear genes in plants. Heredity (Edinb) 1993, 71:630-641.

95. Ennos RA: Estimating the relative rates of pollen and seed migration among plant populations. Heredity (Edinb) 1994, 72:250-259.

96. Nathan R, Klein EK, Robledo-Arnuncio JJ, Revilla E: Dispersal kernels. In Dispersal Ecol Evol. Edited by Clobert J, Baguette M, Benton T, Bullock J. Oxford: Oxford University Press; 2012:187-210. 
97. Piotti A, Leonardi S, Piovani P, Scalfi M, Menozzi P: Spruce colonization at treeline: where do those seeds come from? Heredity (Edinb) 2009, 103:136-145.

98. Vitasse Y, Hoch G, Randin CF, Lenz A, Kollas C, Körner C: Tree recruitment of European tree species at their current upper elevational limits in the Swiss Alps. J Biogeogr 2012, 39:1439-1449.

99. Lesser MR, Jackson ST: Contributions of long-distance dispersal to population growth in colonising Pinus ponderosa populations. Ecol Lett 2013, 16:380-389.

100. Klein EK, Bontemps A, Oddou-Muratorio S: Seed dispersal kernels estimated from genotypes of established seedlings: does densitydependent mortality matter? Methods Ecol Evol 2013, 4:1059-1069.

101. Soubeyrand S, Laine A-L, Hanski I, Penttinen A: Spatiotemporal structure of host-pathogen interactions in a metapopulation. Am Nat 2009, 174:308-320.

102. Dowd M, Meyer R: A Bayesian approach to the ecosystem inverse problem. Ecol Modell 2003, 168:39-55.

103. Khemka A, Bouman CA, Bell MR: Inverse problems in atmospheric dispersion with randomly scattered sensors. Digit Signal Proc 2006, 16:638-651.

104. Manel S, Gaggiotti OE, Waples RS: Assignment methods: matching biological questions with appropriate techniques. Trends Ecol Evol 2005, 20:136-142.

105. Wilson GA, Rannala B: Bayesian inference of recent migration rates using multilocus genotypes. Genetics 2003, 163:1177-1191.

106. Faubet $P$, Gaggiotti OE: A new Bayesian method to identify the environmental factors that influence recent migration. Genetics 2008, 178:1491-1504.

107. Broquet T, Yearsley J, Hirzel AH, Goudet J, Perrin N: Inferring recent migration rates from individual genotypes. Mol Ecol 2009, 18:1048-1060.

108. Robledo-Arnuncio JJ, Navascués M, González-Martínez SC, Gil L: Estimating gametic introgression rates in a risk assessment context: a case study with Scots pine relicts. Heredity (Edinb) 2009, 103:385-393.

109. Robledo-Arnuncio JJ: Wind pollination over mesoscale distances: an investigation with Scots pine. New Phytol 2011, 190:222-233.

110. Robledo-Arnuncio JJ: Joint estimation of contemporary seed and pollen dispersal rates among plant populations. Mol Ecol Resour 2012, 12:299-311.

111. Gaggiotti OE, Brooks SP, Amos W, Harwood J: Combining demographic, environmental and genetic data to test hypotheses about colonization events in metapopulations. Mol Ecol 2004, 13:811-825.

112. Mahura AG, Korsholm US, Baklanov AA, Rasmussen A: Elevated birch pollen episodes in Denmark: contributions from remote sources. Aerobiologia (Bologna) 2007, 23:171-179.

113. Bohrerova Z, Bohrer G, Cho KD, Bolch MA, Linden KG: Determining the viability response of pine pollen to atmospheric conditions during long-distance dispersal. Ecol Appl 2009, 19:656-667.

114. Amm A, Pichot C, Dreyfus P, Davi H, Fady B: Improving the estimation of landscape scale seed dispersal by integrating seedling recruitment. Ann For Sci 2012, 69:845-856

115. Karlsen SR, Ramfjord H, Høgda KA, Johansen B, Danks FS, Brobakk TE: A satellite-based map of onset of birch (Betula) flowering in Norway. Aerobiologia (Bologna) 2008, 25:15-25.

116. Klein EK, Lavigne C, Picault H, Renard M, Gouyon P-H: Pollen dispersal of oilseed rape: estimation of the dispersal function and effects of field dimension. J Appl Ecol 2006, 43:141-151.

117. Ovaskainen O, Rekola H, Meyke E, Arjas E: Bayesian methods for analyzing movements in heterogeneous landscapes from mark-recapture data. Ecology 2008, 89:542-554.

118. Zheng C, Pennanen J, Ovaskainen O: Modelling dispersal with diffusion and habitat selection: analytical results for highly fragmented landscapes. Ecol Modell 2009, 220:1495-1505.

119. Viana DS, Santamaría L, Michot TC, Figuerola J: Allometric scaling of longdistance seed dispersal by migratory birds. Am Nat 2013, 181:649-662.

120. Spear SF, Balkenhol N, Fortin M-J, McRae BH, Scribner K: Use of resistance surfaces for landscape genetic studies: considerations for parameterization and analysis. Mol Ecol 2010, 19:3576-3591.

121. Lander TA, Klein EK, Stoeckel S, Mariette S, Musch B, Oddou-Muratorio S: Interpreting realized pollen flow in terms of pollinator travel paths and land-use resistance in heterogeneous landscapes. Landsc Ecol 2013, 28:1769-1783.

122. Clark JS, Gelfand AE: A future for models and data in environmental science. Trends Ecol Evol 2006, 21:375-380.
123. Figuerola J, Green AJ, Michot TC: Invertebrate eggs can fly: evidence of waterfowl-mediated gene flow in aquatic invertebrates. Am Nat 2005, 165:274-280.

124. Viana DS, Santamaría L, Michot TC, Figuerola J: Migratory strategies of waterbirds shape the continental-scale dispersal of aquatic organisms. Ecography (Cop) 2013, 36:430-438.

125. Wasser SK, Shedlock AM, Comstock K, Ostrander EA, Mutayoba B, Stephens M: Assigning African elephant DNA to geographic region of origin: applications to the ivory trade. Proc Natl Acad Sci U S A 2004, 101:14847-14852.

126. Rundel $\mathrm{CW}$, Wunder MB, Alvarado AH, Ruegg KC, Harrigan $\mathrm{R}$, Schuh $\mathrm{A}$, Kelly JF, Siegel RB, Desante DF, Smith TB, Novembre J: Novel statistical methods for integrating genetic and stable isotope data to infer individual-level migratory connectivity. Mol Ecol 2013, 22:4163-4176.

127. Pella J, Masuda M: Bayesian methods for analysis of stock mixtures. Fish Bull 2001, 99:151-167.

128. Neubauer P, Shima JS, Swearer SE: Inferring dispersal and migrations from incomplete geochemical baselines: analysis of population structure using Bayesian infinite mixture models. Methods Ecol Evol 2013, 4:836-845.

129. Matlack GR: Diaspore size, shape, and fall behavior in wind-dispersed plant species. Am J Bot 1987, 74:1150-1160

130. Tackenberg O, Poschlod P, Bonn S: Assessment of wind dispersal potential in plant species. Ecol Monogr 2003, 73:191-205.

131. Stevens VM, Pavoine S, Baquette M: Variation within and between closely related species uncovers high intra-specific variability in dispersal. Plos One 2010, 5:e11123.

132. Thiede DA, Augspurger CK: Intraspecific variation in seed dispersion of Lepidium campestre (Barassicaceae). Am J Bot 1996, 83:856-866.

133. Dick CW, Etchelecu G, Austerlitz F: Pollen dispersal of tropical trees (Dinizia excelsa: Fabaceae) by native insects and African honeybees in pristine and fragmented Amazonian rainforest. Mol Ecol 2003, 12:753-764.

134. Slavov GT, Leonardi S, Burczyk J, Adams WT, Strauss SH, Difazio SP. Extensive pollen flow in two ecologically contrasting populations of Populus trichocarpa. Mol Ecol 2009, 18:357-373.

135. Chybicki IJ, Burczyk J: Realized gene flow within mixed stands of Quercus robur L. and Q. petraea (Matt.) L. revealed at the stage of naturally established seedling. Mol Ecol 2010, 19:2137-2151.

136. Oddou-Muratorio S, Bontemps A, Klein EK, Chybicki I, Vendramin GG, Suyama Y: Comparison of direct and indirect genetic methods for estimating seed and pollen dispersal in Fagus sylvatica and Fagus crenata. For Ecol Manage 2010, 259:2151-2159.

137. Moran EV, Clark JS: Between-site differences in the scale of dispersal and gene flow in red oak. PLoS One 2012, 7:e36492.

138. Clark JS, Macklin E, Wood L: Stages and spatial scales of recruitment limitation in southern Appalachian forests. Ecol Monogr 1998, 68:213-235.

139. Rodríguez-Pérez J, Larrinaga AR, Santamaría L: Effects of frugivore preferences and habitat heterogeneity on seed rain: a multi-scale analysis. PLoS One 2012, 7:e33246.

140. Morales JM, Garcia D, Martínez D, Rodriguez-Perez J, Herrera JM: Frugivore behavioural details matter for seed dispersal: a multi-species model for Cantabrian thrushes and trees. PLoS One 2013, 8:e65216.

141. Skarpaas $O$, Auhl $R$, Shea $K$ : Environmental variability and the initiation of dispersal: turbulence strongly increases seed release. Proc $R$ Soc B Biol Sci 2006, 273:751-756.

142. Olesen JM, Bascompte J, Elberling H, Jordano P: Temporal dynamics in a pollination network. Ecology 2008, 89:1573-1582.

143. Jansen PA, Bongers F, Hemerik L: Seed mass and mast seeding enhance dispersal by a neotropical scatter-hoarding rodent. Ecol Monogr 2004 74:569-589

144. Soons MB, van der Vlugt C, van Lith B, Heil GW, Klaassen M: Small seed size increases the potential for dispersal of wetland plants by ducks. J Ecol 2008, 96:619-627.

145. Kelly N, Cousens RD, Taghizadeh MS, Hanan JS, Mouillot D: Plants as populations of release sites for seed dispersal: a structural-statistical analysis of the effects of competition on Raphanus raphanistrum. J Ecol 2013, 101:878-888.

146. Chybicki IJ, Burczyk J: Seeing the forest through the trees: comprehensive inference on individual mating patterns in a mixed stand of Quercus robur and Q. petraea. Ann Bot 2013, 112:561-574.

147. Gauzere J, Klein EK, Oddou-Muratorio S: Ecological determinants of mating system within and between three Fagus sylvatica populations along an elevational gradient. Mol Ecol 2013, 22:5001-5015. 
148. Ritland K: Marker-inferred relatedness as a tool for detecting heritability in nature. Mol Ecol 2000, 9:1195-1204

149. Ronce O: How does it feel to be like a rolling stone? Ten questions about dispersal evolution. Annu Rev Ecol Evol Syst 2007, 38:231-253.

150. Cwynar LC, MacDonald GM: Geographical variation of lodgepole pine in relation to population history. Am Nat 1987, 129:463-469.

151. Peroni PA: Seed size and dispersal potential of Acer rubrum (Aceraceae) samaras produced by populations in early and late successional environments. Am J Bot 1994, 81:1428-1434.

152. Fresnillo B, Ehlers BK: Variation in dispersability among mainland and island populations of three wind dispersed plant species. Plant Syst Evol 2007, 270:243-255.

153. Darling E, Samis KE, Eckert CG: Increased seed dispersal potential towards geographic range limits in a Pacific coast dune plant. New Phytol 2008, 178:424-435.

154. Monty A, Mahy G: Evolution of dispersal traits along an invasion route in the wind-dispersed Senecio inaequidens (Asteraceae). Oikos 2010, 119:1563-1570.

155. Cheptou P-O, Carrue O, Rouifed S, Cantarel A: Rapid evolution of seed dispersal in an urban environment in the weed Crepis sancta. Proc Natl Acad Sci U S A 2008, 105:3796-3799.

156. Riba M, Mayol M, Giles BE, Ronce O, Imbert E, van der Velde M, Chauvet S, Ericson L, Bijlsma R, Vosman B, Smulders MJM, Olivieri I: Darwin's wind hypothesis: does it work for plant dispersal in fragmented habitats? New Phytol 2009, 183:667-677.

157. Duputié A, Massol F: An empiricist's guide to theoretical predictions on the evolution of dispersal. Interface Focus 2013, 3:20130028.

158. Donohue K, Polisetty CR, Wender NJ: Genetic basis and consequences of niche construction: plasticity-induced genetic constraints on the evolution of seed dispersal in Arabidopsis thaliana. Am Nat 2005, 165:537-550.

159. Etterson JR, Shaw RG: Constraint to adaptive evolution in response to global warming. Science 2001, 294:151-154.

160. Jordano P: Spatial and temporal variation in the avian-frugivore assemblage of Prunus mahaleb: patterns and consequences. Oikos 1994, 71:479-491.

161. Schupp EW, Jordano P, Gomez JM: Seed dispersal effectiveness revisited: a conceptual review. New Phytol 2010, 188:333-353.

162. Levey DJ: Spatial and temporal variation in Costa Rican fruit and fruit-eating bird abundance. Ecol Monogr 1988, 58:251-269.

163. Morris WF: Predicting the consequence of plant spacing and biased movement for pollen dispersal by honey bees. Ecology 1993, 74:493-500.

164. Greene DF, Johnson EA: Fruit abscission in Acer saccharinum with reference to seed dispersal. Can J Bot 1992, 70:2277-2283.

165. Willson MF, Whelan CJ: Variation of dispersal phenology in a bird-dispersed shrub, Cornus drummondii. Ecol Monogr 1993, 63:151-172.

166. Bishop JG, Schemske DW: Variation in flowering phenology and its consequences for lupines colonizing Mount St. Helens. Ecology 1998, 79:534-546.

167. Skarpaas O, Shea K, Jongejans E: Watch your time step: trapping and tracking dispersal in autocorrelated environments. Methods Ecol Evol 2011, 2:407-415

168. Muller-Landau HC, Wright SJ, Calderón O, Condit R, Hubbell SP: Interspecific variation in primary seed dispersal in a tropical forest. J Ecol 2008, 96:653-667.

169. Irwin AJ, Hamrick JL, Godt MJW, Smouse PE: A multiyear estimate of the effective pollen donor pool for Albizia julibrissin. Heredity (Edinb) 2003, 90:187-194

170. Houle G: Seed dispersal and seedling recruitment of Betula alleghaniensis: spatial inconsistency in time. Ecology 1998, 79:807-818.

171. Iwaizumi MG, Takahashi M, Isoda K, Austerlitz F: Consecutive five-year analysis of paternal and maternal gene flow and contributions of gametic heterogeneities to overall genetic composition of dispersed seeds of Pinus densiflora (Pinaceae). Am J Bot 2013, 100:1896-1904.

172. Petit RJ, Hampe A: Some evolutionary consequences of being a tree. Annu Rev Ecol Evol Syst 2006, 37:187-214.

173. Muller-Landau HC: Seed dispersal in a tropical forest: empirical patterns, their origins and their consequences for forest dynamics. In PhD thesis. Princeton University; 2001.

174. Oddou-Muratorio S, Klein EK, Vendramin GG, Fady B: Spatial vs. temporal effects on demographic and genetic structures: the roles of dispersal, masting and differential mortality on patterns of recruitment in Fagus sylvatica. Mol Ecol 2011, 20:1997-2010.
175. Andrew ME, Ustin SL: The effects of temporally variable dispersal and landscape structure on invasive species spread. Ecol Appl 2010, 20:593-608.

176. Ellner SP, Schreiber SJ: Temporally variable dispersal and demography can accelerate the spread of invading species. Theor Popul Biol 2012, 82:283-298

177. Chesson P, Huntly N: The roles of harsh and fluctuating conditions in the dynamics of ecological communities. Am Nat 1997, 150:519-553.

178. Jacquemyn H, Brys R, Vandepitte K, Honnay O, Roldán-Ruiz I, Wiegand T: A spatially explicit analysis of seedling recruitment in the terrestrial orchid Orchis purpurea. New Phytol 2007, 176:448-459.

179. Wiegand K, Jeltsch F, Ward D: Analysis of the population dynamics of Acacia trees in the Negev desert, Israel with a spatially-explicit computer simulation model. Ecol Modell 1999, 117:203-224.

180. Vellend M: Conceptual synthesis in community ecology. Q Rev Biol 2010, 85:183-206

181. Chave J, Muller-Landau HC, Levin SA: Comparing classical community models: theoretical consequences for patterns of diversity. Am Nat 2002, 159:1-23.

182. Mouquet N, Loreau M: Community patterns in source-sink metacommunities. Am Nat 2003, 162:544-557.

183. Levine JM, Murrell DJ: The community-level consequences of seed dispersal patterns. Annu Rev Ecol Evol Syst 2003, 34:549-574.

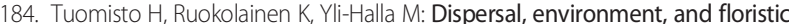
variation of western Amazonian forests. Science 2003, 299:241-244.

185. Smith TW, Lundholm JT: Variation partitioning as a tool to distinguish between niche and neutral processes. Ecography (Cop) 2010, 33:648-655.

186. Condit R, Pitman N, Leigh EG Jr, Chave J, Terborgh J, Foster RB, Núñez P, Vargas H, Aguilar S, Valencia R, Villa G, Muller-Landau H, Losos E, Hubbell SP: Beta-diversity in tropical forest trees. Science 2002, 295:666-669.

187. Magrach A, Larrinaga AR, Santamaria L: Effects of matrix characteristics and interpatch distance on functional connectivity in fragmented temperate rainforests. Conserv Biol 2012, 26:238-247.

188. Magrach A, Larringa AR, Santamaria L: Internal habitat quality determines the effects of fragmentation on austral forest climbing and epiphytic angiosperms. PLoS One 2012, 7:e48473

189. Wright SJ, Hernandez A, Condit R: The bushmeat harvest alters seedling banks by favoring lianas, large seeds, and seeds dispersed by bats, birds, and wind. Biotropica 2007, 39:363-371.

190. Theimer TC, Gehring CA, Green PT, Connell JH: Terrestrial vertebrates alter seedling composition and richness but not diversity in an Australian tropical forest. Ecology 2011, 92:1637-1647.

191. Myers JA, Harms KE: Seed arrival, ecological filters, and plant species richness: a meta-analysis. Ecol Lett 2009, 12:1250-1260.

192. Leibold MA, Holyoak M, Mouquet N, Amarasekare P, Chase JM, Hoopes MF, Holt RD, Shurin JB, Law R, Tilman D, Loreau M, Gonzalez A: The metacommunity concept: a framework for multi-scale community ecology. Ecol Lett 2004, 7:601-613.

193. Holyak M, Leibold MA, Holt RD (Eds): Metacommunities: Spatial Dynamics and Ecological Communities. Chicago and London: University of Chicago Press; 2005.

194. Bolker BM, Pacala SW: Spatial moment equations for plant competition: understanding spatial strategies and the advantages of short dispersal. Am Nat 1999, 153:575-602

195. Dieckmann M, Law R, Metz JAJ: The Geometry of Ecological Interactions: Simplifying Spatial Complexity. Cambridge: Cambridge University Press; 2000.

196. Murrell DJ, Law R: Heteromyopia and the spatial coexistence of similar competitors. Ecol Lett 2003, 6:48-59.

197. Detto M, Muller-Landau HC: Fitting ecological process models to spatial patterns using scalewise variances and moment equations. Am Nat 2013, 181:E68-E82.

198. Augspurger CK, Kitajima K: Experimental studies of seedling recruitment from contrasting seed distributions. Ecology 1992, 73:1270-1284.

199. Pacala SW, Canham CD, Saponara J, Silander JA, Kobe RK, Ribbens E: Forest models defined by field measurements: estimation, error analysis and dynamics. Ecol Monogr 1996, 66:1-43.

200. Svenning J-C, Skov F: Could the tree diversity pattern in Europe be generated by postglacial dispersal limitation? Ecol Lett 2007, 10:453-460.

201. McLachlan JS, Clark JS, Manos PS: Molecular indicators of tree migration capacity under rapid climate change. Ecology 2005, 86:2088-2098.

202. Rowe KC, Heske EJ, Brown PW, Paige KN: Surviving the ice: Northern refugia and postglacial colonization. Proc Natl Acad Sci U S A 2004, 101:10355-10359. 
203. Davis MB, Shaw RG: Range shifts and adaptive responses to Quaternary climate change. Science 2001, 292:673-679.

204. Phillips BL, Brown GP, Shine R: Life-history evolution in range-shifting populations. Ecology 2010, 91:1617-1627.

205. Duputié A, Massol F, Chuine I, Kirkpatrick M, Ronce O: How do genetic correlations affect species range shifts in a changing environment? Ecol Lett 2012, 15:251-259.

206. Chevin L-M, Collins S, Lefèvre F: Phenotypic plasticity and evolutionary demographic responses to climate change: taking theory out to the field. Funct Ecol 2013, 27:967-979.

207. Lavergne S, Mouquet N, Thuiller W, Ronce O: Biodiversity and climate change: integrating evolutionary and ecological responses of species and communities. Annu Rev Ecol Evol Syst 2010, 41:321-350.

208. Morin X, Viner D, Chuine I: Tree species range shifts at a continental scale: new predictive insights from a process-based model. J Ecol 2008, 96:784-794.

209. Honnay O, Verheyen K, Butaye J, Jacquemyn H, Bossuyt B, Hermy M: Possible effects of habitat fragmentation and climate change on the range of forest plant species. Ecol Lett 2002, 5:525-530.

210. Kirkpatrick M: Patterns of quantitative genetic variation in multiple dimensions. Genetica 2009, 136:271-284.

211. Walsh B, Blows MW: Abundant genetic variation + strong selection = multivariate genetic constraints: a geometric view of adaptation. Annu Rev Ecol Evol Syst 2009, 40:41-59.

212. Keith DA, Akçakaya HR, Thuiller W, Midgley GF, Pearson RG, Phillips SJ, Regan HM, Araújo MB, Rebelo TG: Predicting extinction risks under climate change: coupling stochastic population models with dynamic bioclimatic habitat models. Biol Lett 2008, 4:560-563.

213. Anderson BJ, Akçakaya HR, Araújo MB, Fordham DA, Martinez-Meyer E, Thuiller W, Brook BW: Dynamics of range margins for metapopulations under climate change. Proc Bio/ Sci 2009, 276:1415-1420.

214. Fordham DA, Resit Akçakaya $H$, Araújo MB, Elith J, Keith DA, Pearson $R$, Auld TD, Mellin C, Morgan JW, Regan TJ, Tozer M, Watts MJ, White M, Wintle BA, Yates C, Brook BW: Plant extinction risk under climate change: are forecast range shifts alone a good indicator of species vulnerability to global warming? Glob Chang Biol 2012, 18:1357-1371.

215. Schurr FM, Pagel J, Cabral JS, Groeneveld J, Bykova O, O'Hara RB, Hartig F, Kissling WD, Linder HP, Midgley GF, Schröder B, Singer A, Zimmermann NE: How to understand species' niches and range dynamics: a demographic research agenda for biogeography. J Biogeogr 2012, 39:2146-2162.

216. Kuparinen A, Schurr FM: A flexible modelling framework linking the spatio-temporal dynamics of plant genotypes and populations: application to gene flow from transgenic forests. Ecol Modell 2007, 202:476-486.

217. Kearney M, Porter WP, Williams C, Ritchie S, Hoffmann AA: Integrating biophysical models and evolutionary theory to predict climatic impacts on species' ranges: the dengue mosquito Aedes aegypti in Australia. Funct Ecol 2009, 23:528-538.

218. Kissling WD, Dormann CF, Groeneveld J, Hickler T, Kühn I, Mclnerny GJ, Montoya JM, Römermann C, Schiffers K, Schurr FM, Singer A, Svenning J-C, Zimmermann NE, O'Hara RB: Towards novel approaches to modelling biotic interactions in multispecies assemblages at large spatial extents. J Biogeogr 2012, 39:2163-2178.

219. Cabral JS, Kreft H: Linking ecological niche, community ecology and biogeography: insights from a mechanistic niche model. J Biogeogr 2012, 39:2212-2224

220. Kokko H, López-Sepulcre A: The ecogenetic link between demography and evolution: can we bridge the gap between theory and data? EcO Lett 2007, 10:773-782.

221. Garant D, Forde SE, Hendry AP: The multifarious effects of dispersal and gene flow on contemporary adaptation. Funct Ecol 2007, 21:434-443.

222. Kuparinen A, Savolainen O, Schurr FM: Mortality can promote evolutionary adaptation of forest trees to climate change. For Ecol Manage 2010, 259:1003-1008.

223. Aguilée $R$, Shaw FH, Rousset F, Shaw RG, Ronce O: How does pollen versus seed dispersal affect niche evolution? Evolution (N Y) 2013, 67:792-805.

224. Soons MB, Bullock JM: Non-random seed abscission, long-distance wind dispersal and plant migration rates. J Ecol 2008, 96:581-590.

225. Nathan R, Horvitz N, He Y, Kuparinen A, Schurr FM, Katul GG: Spread of North American wind-dispersed trees in future environments. Ecol Lett 2011, 14:211-219.
226. Hampe A: Plants on the move: the role of seed dispersal and initial population establishment for climate-driven range expansions. Acta Oecol 2011, 37:666-673.

227. Bullock JM, White SM, Prudhomme C, Tansey C, Perea R, Hooftman DAP: Modelling spread of British wind-dispersed plants under future wind speeds in a changing climate. J Ecol 2012, 100:104-115.

228. Thompson SE, Katul GG: Implications of nonrandom seed abscission and global stilling for migration of wind-dispersed plant species. Glob Chang Biol 2013, 19:1720-1735.

229. Cunze S, Heydel F, Tackenberg O: Are plant species able to keep pace with the rapidly changing climate? PLoS One 2013, 8:e67909.

230. Jackson ST, Betancourt JL, Booth RK, Gray ST: Ecology and the ratchet of events: climate variability, niche dimensions, and species distributions. Proc Natl Acad Sci U S A 2009, 106(Suppl 2):19685-19692.

231. Donohue K, Rubio de Casas R, Burghardt L, Kovach K, Willis CG: Germination, postgermination adaptation, and species ecological ranges. Annu Rev Ecol Evol Syst 2010, 41:293-319.

232. Walck JL, Hidayati SN, Dixon KW, Thompson K, Poschlod P: Climate change and plant regeneration from seed. Glob Chang Biol 2011, 17:2145-2161.

233. Bykova O, Chuine I, Morin X, Higgins SI: Temperature dependence of the reproduction niche and its relevance for plant species distributions. J Biogeogr 2012, 39:2191-2200.

234. Yeaman S, Jarvis A: Regional heterogeneity and gene flow maintain variance in a quantitative trait within populations of lodgepole pine. Proc R Soc B 2006, 273:1587-1593.

235. Caughlin TT, Ferguson JM, Lichstein JW, Bunyavejchewin S, Levey DJ: The importance of long-distance seed dispersal for the demography and distribution of a canopy tree species. Ecology 2014, 95:952-962.

236. Hodkinson DJ, Thompson K: Plant dispersal: the role of man. J App/ Ecol 1997, 34:1484-1496.

237. Wichmann MC, Alexander MJ, Soons MB, Galsworthy S, Dunne L, Gould R, Fairfax C, Niggemann M, Hails RS, Bullock JM: Human-mediated dispersal of seeds over long distances. Proc Biol Sci 2009, 276:523-532.

238. Wright SJ: Seed dispersal in anthropogenic landscapes. In Seed Dispersal: Theory and its Application in a Changing World. Edited by Dennis AJ, Schupp EW, Green RA, Wescott DA. Oxfordshire: CAB International; 2007:599-614.

239. McConkey KR, Prasad S, Corlett RT, Campos-Arceiz A, Brodie JF, Rogers H, Santamaria L: Seed dispersal in changing landscapes. Biol Conserv 2012, 146:1-13.

240. Sala OE, Chapin FS, Armesto JJ, Berlow E, Bloomfield J, Dirzo R, Huber-Sanwald E, Huenneke LF, Jackson RB, Kinzig A, Leemans R, Lodge DM, Mooney HA, Oesterheld M, Poff NL, Sykes MT, Walker BH, Walker M, Wall DH: Global biodiversity scenarios for the year 2100 . Science 2000, 287:1770-1774.

241. Brook BW, Sodhi NS, Bradshaw CJA: Synergies among extinction drivers under global change. Trends Ecol Evol (Personal Ed) 2008, 23:453-460.

242. Higgins SI, Richardson DM: Predicting plant migration rates in a changing world: the role of long-distance dispersal. Am Nat 1999, 153:464-475.

243. Neilson RP, Pitelka LF, Solomon AM, Nathan R, Midgley GF, Fragoso JMV, Lischke H, Thompson K: Forecasting Regional to Global Plant Migration in Response to Climate Change. Bioscience 2005, 55:749.

244. Tylianakis JM, Didham RK, Bascompte J, Wardle DA: Global change and species interactions in terrestrial ecosystems. Ecol Lett 2008, 11:1351-1363.

245. Aguilar R, Ashworth L, Galetto L, Aizen MA: Plant reproductive susceptibility to habitat fragmentation: review and synthesis through a meta-analysis. Ecol Lett 2006, 9:968-980.

246. Eckert CG, Kalisz S, Geber MA, Sargent R, Elle E, Cheptou P-O, Goodwillie C, Johnston MO, Kelly JK, Moeller DA, Porcher E, Ree RH, Vallejo-Marín M, Winn AA: Plant mating systems in a changing world. Trends Ecol Evol 2010, 25:35-43.

247. Jordano P: Fruits and frugivory. In Seeds: The Ecology of Regeneration in Plant Communities. Edited by Fenner M. Wallinford, UK: CABI Publ; 2000:125-166

248. Traveset A, Richardson DM: Biological invasions as disruptors of plant reproductive mutualisms. Trends Ecol Evol 2006, 21:208-216.

249. Cordeiro NJ, Howe HF: Forest fragmentation severs mutualism between seed dispersers and an endemic African tree. Proc Natl Acad Sci U S A 2003, 100:14052-14056.

250. García D, Chacoff NP: Scale-dependent effects of habitat fragmentation on hawthorn pollination, frugivory, and seed predation. Conserv Bio 2007, 21:400-411. 
251. Markl JS, Schleuning M, Forget PM, Jordano P, Lambert JE, Traveset A, Wright SJ, Böhning-Gaese K: Meta-analysis of the effects of human disturbance on seed dispersal by animals. Conserv Biol 2012, 26:1072-1081.

252. Magrach A, Laurance WF, Larrinaga AR, Santamaria L: Meta-Analysis of the effects of forest fragmentation on interspecific Interactions. Conserv Biol 2014. doi:10.1111/cobi.12304.

253. Galetti M, Donatti Cl, Pires AS, Guimaraes PR, Jordano P: Seed survival and dispersal of an endemic Atlantic forest palm: the combined effects of defaunation and forest fragmentation. Bot J Linn Soc 2006, 151:141-149.

254. Cramer JM, Mesquita RCG, Bruce Williamson G: Forest fragmentation differentially affects seed dispersal of large and small-seeded tropical trees. Biol Conserv 2007, 137:415-423.

255. Steffan-Dewenter I, Münzenberg U, Tscharntke T: Pollination, seed set and seed predation on a landscape scale. Proc Biol Sci 2001, 268:1685-1690.

256. Pearson RG, Dawson TP: Long-distance plant dispersal and habitat fragmentation: identifying conservation targets for spatial landscape planning under climate change. Biol Conserv 2005, 123:389-401.

257. Williams P, Hannah L, Andelman S, Midgley G, Araujo M, Hughes G, Manne L, Martinez-Meyer E, Pearson R: Planning for climate change: identifying minimum-dispersal corridors for the Cape Proteaceae. Conserv Biol 2005, 19:1063-1074.

258. Damschen El, Brudvig LA, Haddad NM, Levey DJ, Orrock JL, Tewksbury JJ: The movement ecology and dynamics of plant communities in fragmented landscapes. Proc Natl Acad Sci U S A 2008, 105:19078-19083.

259. Townsend PA, Levey DJ: An experimental test of whether habitat corridors affect pollen transfer. Ecology 2005, 86:466-475.

260. Zabel CJ, Roberts LM, Mulder BS, Stauffer HB, Dunk JR, Wolcott K, Solis D, Gertsch M, Woodbridge B, Wright A, Goldsmith G, Keckler C: A collaborative approach in adaptive management at a large-landscape scale. In Predicting species ocurrence: issues of accuracy and scale. Edited by Scott JM, Heglund PJ, Morrison ML, Haufler JB, Raphael MG, Wall WA, Samson FB. Washington: Island Press; 2002.

261. Hobbs RJ, Suding KN, Seastedt TR: Management of novel ecosystems: are novel approaches required? Front Ecol Environ 2008, 6:547-553.

262. Hamrick JL: Response of forest trees to global environmental changes. For Ecol Manage 2004, 197:323-335.

263. Kuparinen A, Katul G, Nathan R, Schurr FM: Increases in air temperature can promote wind-driven dispersal and spread of plants. Proc Biol Sci 2009, 276:3081-3087.

264. Trakhtenbrot A, Nathan R, Perry G, Richardson DM: The importance of long-distance dispersal in biodiversity conservation. Divers Distrib 2005, 11:173-181.

265. Kuparinen A, Markkanen T, Riikonen H, Vesala T: Modeling air-mediated dispersal of spores, pollen and seeds in forested areas. Ecol Modell 2007, 208:177-188.

266. Damschen El, Baker DV, Bohrer G, Nathan R, Orrock JL, Turner JR, Brudvig LA, Haddad NM, Levey DJ, Tewksbury JJ: How fragmentation and corridors affect wind dynamics and seed dispersal in open habitats. Proc Natl Acad Sci U S A 2014, 111:3484-3489.

267. Stockwell CA, Hendry AP, Kinnison MT: Contemporary evolution meets conservation biology. Trends Ecol Evol 2003, 18:94-101.

268. Santamaría L, Méndez PF: Evolution in biodiversity policy - current gaps and future needs. Evol App/ 2012, 5:202-218.

269. Lenormand T: Gene flow and the limits to natural selection. Trends Ecol Evol 2002, 17:183-189.

270. Lopez S, Rousset F, Shaw FH, Shaw RG, Ronce O: Migration load in plants: role of pollen and seed dispersal in heterogeneous landscapes. J Evol Biol 2008, 21:294-309.

271. Tallmon DA, Luikart G, Waples RS: The alluring simplicity and complex reality of genetic rescue. Trends Ecol Evol 2004, 19:489-496.

272. Laikre L, Schwartz MK, Waples RS, Ryman N, GeM W: Compromising genetic diversity in the wild: unmonitored large-scale release of plants and animals. Trends Ecol Evol 2010, 25:520-529.

273. Harrison S: How natural habitat patchiness affects the distribution of diversity in Californian serpentine chaparral. Ecology 1997, 78:1898-1906.

274. Freestone $\mathrm{AL}$, Inouye BD: Dispersal limitation and environmental heterogeneity shape scale-dependent diversity patterns in plant communities. Ecology 2006, 87:2425-2432.
275. Roschewitz I, Gabriel D, Tscharntke T, Thies C: The effects of landscape complexity on arable weed species diversity in organic and conventional farming. J Appl Ecol 2005, 42:873-882

276. Plantegenest M, Le May C, Fabre F: Landscape epidemiology of plant diseases. J R Soc Interface 2007, 4:963-972

277. Urban MC, De Meester L, Vellend M, Stoks R, Vanoverbeke J: A crucial step toward realism: responses to climate change from an evolving metacommunity perspective. Evol Appl 2012, 5:154-167.

doi:10.1186/s40462-014-0016-3

Cite this article as: Robledo-Arnuncio et al: Space, time and complexity in plant dispersal ecology. Movement Ecology 2014 2:16.

\section{Submit your next manuscript to BioMed Central and take full advantage of:}

- Convenient online submission

- Thorough peer review

- No space constraints or color figure charges

- Immediate publication on acceptance

- Inclusion in PubMed, CAS, Scopus and Google Scholar

- Research which is freely available for redistribution

Submit your manuscript at www.biomedcentral.com/submit

C) Biomed Central 